\title{
The incomplete male
}

During the last 20 years a great deal has been learned about the aetiology and management of intersex states. In particular, the importance of congenital adrenal hyperplasia as a cause of female pseudohermaphroditism has become widely recognised. Cytogenetic methods have clarified the cause of the genital anomalies associated with sex chromosome abnormalities and while techniques such as banding and $Y$-fluorescence have failed to define the aetiology of true hermaphroditism, this has not generally interfered with correct clinical management. However, the investigation and management of patients with a male chromosomal complement but incomplete masculinisation of the external genitalia (male pseudohermaphroditism) remain among the most intriguing and difficult aspects of paediatric endocrinology.

Male intersexuality represents a disturbance of the normal process of fetal sexual differentiation and is characterised by genital ambiguity and deficient masculinisation at puberty. In his classical experiments with gonadectomy in fetal rabbits, Jost ${ }^{1}$ showed that the mammalian embryo has an inherent tendency to develop as a female. The development of the male phenotype is more complex than that of the female and depends on the differentiation and action of the fetal testis. Human testicular differentiation appears to be controlled by the $Y$ chromosome. At a critical period in fetal life (10-18 weeks after fertilisation) the testicular Leydig cells secrete testosterone which directly stimulates the formation of the internal genitalia (the vas deferens, epididymis, and seminal vesicles) from the Wolffian ducts. The external genitalia are masculinised by dihydrotestosterone which is derived from testosterone by the action of the enzyme 5- $\alpha$-reductase. A second testicular hormone known as muellerian inhibiting factor, a polypeptide, is secreted during the same period by the Sertoli cells and causes suppression of the female muellerian ducts. ${ }^{2}$

The aetiology of male intersexuality may be divided into three basic categories ${ }^{3}$ (Table). These are abnormal testicular differentiation, abnormal testicular function, and target organ unresponsiveness to androgen.

\section{Abnormal testicular differentiation}

This may result from a defect of the testis-determining genes on the short arm of the $Y$ chromosome, or from

\section{Table Aetiological categories of male intersexuality}

\begin{tabular}{l} 
Abnormal testicular differentiation \\
Defect of the Y chromosome \\
Leydig cell hypoplasia \\
Abnormal testicular function \\
Gonadotrophin deficiency \\
Dysmorphic syndromes (Smith-Lemli-Opitz) \\
Disorders of testosterone biosynthesis \\
Target organ unresponsiveness to androgen \\
Androgen receptor defects \\
$5 \alpha$-reductase deficiency \\
\hline
\end{tabular}

a reduction in the $\mathrm{XY}$ cell line in the fetal gonad. The testes are dysgenetic and both Leydig and Sertoli cell functions are affected causing incomplete masculinisation and persistence of the muellerian structures. Inadequate masculinisation may also result from primary Leydig cell hypoplasia. ${ }^{4}$

\section{Abnormal testicular function}

This is most commonly due to the congenital deficiency of one of the enzymes involved in the different steps of testosterone biosynthesis. The enzymes normally participating in this pathway are, 20-22 desmolase, ${ }^{5}$ 3- $\beta$-hydroxydehydrogenase, ${ }^{6} 17$ $\alpha$-hydroxylase, ${ }^{7}$ 17-20 desmolase, ${ }^{8}$ and 17-ketosteroid reductase. ${ }^{9}$ These enzyme deficiencies which usually occur both in gonads and adrenals, are becoming increasingly recognised as causes of male intersexuality. Muellerian suppression is unaffected and the degree of genital ambiguity usually reflects the severity of the enzyme defect. The presence of salt-loss (in 20-22 desmolase and 3- $\beta$-hydroxydehyrogenase deficiencies) or hypertension (in 17 $\alpha$-hydroxylase deficiency) may provide a clinical clue to one of these disorders. In general, however, fairly sophisticated biochemical techniques, coupled with the measurement of testosterone and its precursor hormones before and after HCG stimulation of the prepubertal testis, are necessary to characterise fully the enzyme deficiency.

Another potential cause of abnormal testicular function is impaired fetal gonadotrophin production. Prader $^{10}$ reported a child with a male karyotype and female genitalia who was found to have LH deficiency. This mechanism may also contribute to the poor virilisation in some dysmorphic states such as the Smith-Lemli-Opitz syndrome. 


\section{Androgen target organ unresponsiveness}

The third aetiological category accounts for most cases of male intersexuality. Included in this category are complete and incomplete testicular feminisation, and deficiency of the enzyme 5 - $\alpha$-reductase. The androgenic action of testosterone and dihydrotestosterone is normally initiated by the binding of the steroid to a specific cytoplasmic receptor protein. The androgen receptor is under the control of a gene or set of genes on the $X$ chromosome. ${ }^{11}$ In testicular feminisation there is thought to be a mutation of one such gene leading to a lack of androgen binding. In vitro receptor studies ${ }^{12}$ have demonstrated impaired dihydrotestosterone binding in fibroblasts cultured from the perineal skin of patients with this form of androgen unresponsiveness. In complete testicular feminisation the phenotype is totally female and the affected subjects are brought up as girls. Incomplete testicular feminisation ${ }^{13}$ is presumably due to a partial defect ${ }^{14}$ at the receptor level, the genetics of which are not clear. These subjects have a varying degree of fetal masculinisation and some virilisation at puberty, usually with breast development. The clinical syndromes of Reifenstein, Lubs, and Gilbert-Dryfus are now also thought to be examples of a partial receptor defect. ${ }^{15}$ They emphasise the clinical heterogeneity of this aetiological category.

Adult patients with androgen insensitivity have a characteristic hormonal profile. There is simultaneous increase in plasma androgen and LH concentrations, indicating a disturbance of the negative feedback control of pituitary gonadotrophin secretion. This profile normally manifests itself only at puberty ${ }^{16}$ and is therefore of limited diagnostic value. However there is some evidence that markedly raised levels of both androgens and LH during the first 6 months of life-when the pituitary axis is particularly active-may indicate a receptor defect and hence predict a future defect in pubertal masculinisation.

Deficiency of the enzyme 5 - $\alpha$-reductase is a recently established disorder and was first described in 1974 by Imperato-McGinley et al. ${ }^{17,18}$ who reported 24 cases of male intersexuality in an isolated community in the Dominican Republic. These patients were shown to have impaired conversion of circulating testosterone to dihydrotestosterone and an inherited deficiency of 5 - $\alpha$-reductase was suggested as the primary abnormality. The external genitalia in the prepubertal subjects were essentially female but normal male internal genitalia were present. At puberty there was marked penile growth with male gender identity and normal spermatogenesis. Walsh et al. ${ }^{19}$ described a similar patient in whom they demonstrated an absence of dihydro testosterone formation in genital skin, although the concentration of circulating dihydrotestosterone was? normal. In the short report on page 751, Greene et al $\overrightarrow{\overline{\mathrm{s}}}$ report a further case of 5- $\alpha$-reductase deficiency? It therefore appears that decreased conversion of testosterone to dihydrotestosterone, or deficiencye of 5- $\alpha$-reductase in external genital tissues, causes a form of male intersexuality which is characterised? by the lack of fetal masculinisation of the externats genitalia which are dihydrotestosterone dependent $\overrightarrow{0}$ This contrasts with the normal formation of theinternal genitalia and normal pubertal virilisation which are brought about by testosterone itself.

The wide variety of causes of male intersexuality? may make it difficult to decide on the most approw priate gender for some males born with genitaio ambiguity. The choice of sex may be made moreo difficult by the impossibility of predicting the degree of masculinisation and penile growth at puberty? Yet, for successful gender identification it is impor $\overline{\text { is }}$ tant that the decision whether the child should bed reared as a boy or a girl is made as soon after birth as possible.

Generally, there is normal tissue responsiveness $\stackrel{\mathbb{D}}{-}$ to androgens in those cases which are due to defectige testicular function in fetal life, and masculinisationoo may be anticipated as a result of androgen thera in adolescence. In contrast, normal testosterone a ad dihydrotestosterone secretion after HCG $^{20}$ suggests that the genital defect is due to tissue unresponsive-n ness. Pubertal masculinisation in this group is mucho less certain and the presence of a small phallus may make the choice of female gender preferable. There응 is an urgent need for an in vitro test to quantitate androgen responsiveness in the prepubertal child. Evain et al. ${ }^{21}$ recently showed that the dihydrotestosterone cytoplasmic receptor may be measuredô directly from the analysis of a fragment of perineal:skin. This technique however is still being developed 3 . and is not generally available for clinical use.

In doubtful cases there is a place for an early trial of testosterone therapy before the final decision on the most appropriate gender for the child is made. $>$ Appreciable growth of the phallus after 3 injectionso of depot testosterone $(25-50 \mathrm{mg})$, at monthly intervals, suggests that further virilisation will occuro at the time of puberty, either as a result of endo- $N$ genous androgen secretion or further testosterone $\mathbb{E}_{\mathcal{N}}^{N}$ therapy. This penile growth also has the advantageo of simplifying any subsequent operation for correc-o tion of chordee and repair of hypospadias. Cases which show a very poor response to testosterone, or $\stackrel{+}{+}$ which have no appreciable erectile tissue in the 0 phallus, may fare better as girls. 


\section{References}

${ }^{1}$ Jost, A. (1953). Problems of fetal endocrinology. The gonadal and hypophyseal hormones. Recent Progress in Hormone Research, 8, 379-418.

${ }^{2}$ Blanchard, M-G., and Josso, N. (1974). Source of the antimüllerian hormone synthesized by the fetal testis: müllerian-inhibiting activity of fetal bovine Sertoli cells in tissue culture. Pediatric Research, 8, 968-971.

${ }^{3}$ Imperato-McGinley, J., and Peterson, R. E. (1976). Male pseudohermaphroditism: the complexities of male phenotypic development. American Journal of Medicine, 61, 251-272.

${ }^{4}$ Brown, D. M., Markland, C., and Dehner, L. P. (1978). Leydig cell hypoplasia: a cause of male pseudohermaphroditism. Journal of Clinical Endocrinology and Metabolism, 46, 1-7.

${ }^{5}$ Prader, A., and Anders, G. J. P. A. (1962). Zur Genetik der kongenitalen Lipoidyhyperplasie der Nebennieren. Helvetica paediatrica acta, 17, 285-289.

${ }^{6}$ Bongiovanni, A. M. (1961). Unusual steroid pattern in congenital adrenal hyperplasia: deficiency of $3 \beta$-hydroxydehydrogenase. Journal of Clinical Endocrinology and Metabolism, 21, 860-862.

${ }^{7}$ Biglieri, E. G., Herron, M. A., and Brust, N. (1966). 17Hydroxylation deficiency in man. Journal of Clinical Investigation, 45, 1946-1954.

${ }^{8}$ Zachmann, M., Völlmin, J. A., Hamilton, W., and Prader, A. (1972). Steroid 17-20 desmolase deficiency. A new cause of male pseudohermaphroditism. Clinical Endocrinology, 1, 369-385.

${ }^{9}$ Saez, J. M., De Peretti, E., Morerra, A. M., David, M., and Bertrand, J. (1971). Familial male pseudohermaphroditism with gynecomastia due to a testicular 17ketosteroid reductase deficiency. Journal of Clinical Endocrinology and Metabolism, 32, 604-610.

${ }^{10}$ Prader, A., Illig, R., and Zachmann, M. (1976). Prenatal LH-deficiency as possible cause of male pseudohermaphroditism, hypospadias, hypogenitalism, and cyptorchidism (abstract). Pediatric Research, 10, 883.

${ }^{11}$ Ohno, S. (1976). Major regulatory genes for mammalian sexual development. Cell, 7, 315-321.

${ }^{12}$ Keenan, B. S., Meyer, W. J., Hajian, A., and Migeon, J. (1975). Androgen receptor in human skin fibroblastscharacterization of a specific $17 \beta$-hydroxy-5- $\alpha$-androstan 3one protein complex in cell sonicates and nuclei. Steroids, 25, 535-552.
${ }^{13}$ Wilson, J. D., Herrod, M. J., Goldstein, J. L., Hemsell, D. L., and MacDonald, P. C. (1974). Familial incomplete male pseudohermaphroditism Type I. New England Journal of Medicine, 290, 1097-1103.

${ }^{14}$ Amrhein, J. A., Meyer, W. J., Jones, K. W., and Migeon, C. J. (1976). Androgen insensitivity in man: evidence for genetic heterogeneity. Proceedings of the National Academy of Sciences of the United States of America, 73, 891-894.

${ }^{15}$ Amrhein, J. A., Klingensmith, G. J., Walsh, P. C., McKusick, V. A., and Migeon, C. J. (1977). Partial androgen insensitivity. The Reifenstein syndrome revisited. New England Journal of Medicine, 297, 350-356.

${ }^{16}$ Savage, M. O., Chaussain, J. L., Evain, D., Roger, M., Canlorbe, P., and Job, J. C. (1978). Endocrine studies in male pseudohermaphroditism in childhood and adolescence. Clinical Endocrinology, 8, 219-231.

${ }^{17}$ Imperato-McGinley, J., Guerrero, L., Gautier, T., and Peterson, R. E. (1974). Steroid 5 5 -reductase deficiency in man: an inherited form of male pseudohermaphroditism. Science, 186, 1213-1219.

${ }^{18}$ Peterson, R. E., Imperato-McGinley, J., Gautier, T., and Sturia, E. (1977). Male pseudohermaphroditism due to steroid 5- $\alpha$-reductase deficiency. American Journal of Medicine, 62, 170-191.

${ }^{19}$ Walsh, P. C., Madden, J. D., Harrod, M. J., Goldstein, J. L., MacDonald, P. C., and Wilson, J. D. (1974). Familial incomplete male pseudohermaphroditism Type II. New England Journal of Medicine, 291, 944-949.

${ }^{20}$ Grant, D. B., Laurance, B. M., Atherden, S. M., and Ryness, J. (1976). HCG stimulation test in children with abnormal sexual development. Archives of Disease in Childhood, 51, 596-601.

${ }^{21}$ Evain, D., Savage, M. O., and Binet, E. (1977). A specific and rapid determination of human skin dihydrotestosterone cytosol receptor. Journal of Clinical Endocrinology and Metabolism, 45, 363-366.

\section{O. Savage AND D. B. Grant Institute of Child Health, and Hospital for Sick Children, Great Ormond Street, London WC1N $3 J H$}

Correspondence to Dr M. O. Savage, Department of Growth and Development, Institute of Child Health, 30 Guilford Street, London WC1N 1EH. 